\title{
O IMPACTO DO RESULTADO DA AVALIAÇÃO NA DIMENSÃO SOCIOAFETIVA DO ESTUDANTE A PARTIR DAS HISTÓRIAS EM QUADRINHOS DE CHICO BENTO
}

\author{
Fabiula Campos Falcão Fagundes* \\ Gelson Vanderlei Weschenfelder ${ }^{* *}$
}

\begin{abstract}
RESUMO: Esta pesquisa de cunho teórico, do tipo bibliográfico, tem como problemática: quais são os conteúdos difundidos nas histórias em quadrinhos do personagem Chico Bento, em relação ao impacto da avaliação na dimensão sócioafetiva do estudante? O corpus investigativo está composto por quatro tirinhas da Revista Chico Bento, disponibilizadas no Aplicativo Banca da Mônica, utilizado para os dispositivos móveis (celular). Os dados serão analisados por meio da Técnica de Análise de Conteúdo, proposta por Bardin (2016). Ao eleger como objeto analítico os conteúdos sobre avaliação difundidos pelas Histórias em Quadrinhos, tem-se presente que tais histórias são formadoras de opinião e podem influenciar as concepções das crianças leitoras, corroborando ou refutando o que as mesmas entendem e vivenciam nos processos de avaliação no contexto escolar. Os resultados demonstram como a avaliação da aprendizagem aplicada de forma equivocada causa impacto na dimensão socioafetiva do estudante. O referencial teórico do estudo está alicerçado nos pressupostos sobre avaliação de autores tais como Hoffmann (1995), Esteban (2009), Vasconcellos (2008), Luckesi (2010) e Moretto (2010). Com relação às Histórias em Quadrinhos, buscamos aportes nos pressupostos de Moya (1977) e Weschenfelder (2011); vinculado aos grupos de pesquisa Práticas Educativas e Indicadores de Qualidade, e o segundo, Universos Paralelos: Arte Sequencial, Mediação Cultural e práticas pedagógicas, ambos pertencentes ao Programa de Pós-graduação da Universidade La Salle.
\end{abstract}

Palavras-chave: Avaliação; Ensino Fundamental; História em Quadrinhos.

\section{THE IMPACT OF THE EVALUATION RESULT ON THE STUDENT'S SOCIO-AFFECTIVE DIMENSION FROM THE STORIES IN CHICO BENTO'S COMICS}

\begin{abstract}
This bibliographic type theoretical research has as question: what are the contents disseminated in the comic books of the character Chico Bento, in relation to the impact of the evaluation on the student's affective social dimension? The investigative corpus consists of four comic strips from Revista Chico Bento, available on the Banca da Mônica App, used for mobile devices (cell phone). The data will be analyzed using the Content Analysis Technique, proposed by Bardin (2016). When choosing the content about evaluation disseminated by Comics, as an analytical object, it is borne in mind that such stories are opinion makers and can influence the conceptions of children readers, corroborating or refuting what they understand and experience in the evaluation processes in the school context. The results demonstrate how the assessment of misapplied learning impacts the student's socio-affective dimension. The theoretical framework of the study is based on assumptions about evaluation from authors such as Hoffmann (1995), Esteban (2009), Vasconcellos (2008), Luckesi (2010) and Moretto (2010). With regard to Comics, we seek contributions based on the assumptions of Moya (1977) and Weschenfelder (2011); linked to the Educational Practices and Quality Indicators research groups, and the second, Parallel Universes: Sequential Art, Cultural Mediation and pedagogical practices, both belonging to the La Salle University Graduate Program.
\end{abstract}

Keywords: Evaluation; Elementary School; Comic books

\footnotetext{
* Mestre em Educação pelo PPG de Educação da Universidade LaSalle. Graduada em Pedagogia. E-mail: fabiulafalcaofag@gmail.com Orcid: 0000-0002-7505-5853

** Pós doc no PPG em Processos e Manifestações Culturais, na Universidade Feevale. Doutor/Mestre em Educação, e Graduado em Filosofia. E-mail: gellfilo@gmail.com. Orcid: 0000-0002-6571-8027
} 


\section{INTRODUÇÃO}

Diretamente da Vila Abobrinha, mais especificamente da turma da professora Marocas, universo criado pelo grande cartunista Mauricio de Sousa, invadimos a sala de aula representada nessas HQs com a premissa de analisar e comparar a metodologia abordada para avaliar os educandos desta escola de campo, detendo nossos olhares nas vivências do protagonista Chico Bento, esse que representa muitos alunos que acabam reféns do processo de avaliação da aprendizagem. Escolhemos as Histórias em quadrinhos, pois se constituem um artefato cultural, por representar fragmentos de nosso cotidiano, neste caso as tirinhas do personagem Chico Bento, pois essas abordam situações pertinentes ao ambiente escolar que se enquadram no que presenciamos no âmbito escolar.

Diante à metodologia, partimos do Aplicativo Banca da Mônica, onde selecionamos quatro tirinhas, histórias em quadrinhos curtas do Personagem Chico Bento, das quais foram submetidas à Técnica de Análise de Conteúdo, proposta por Bardin (2016). Técnica que é dividida, em três etapas, a saber: pré-análise, etapa em que se realiza uma leitura flutuante do material; exploração do material, em que são estabelecidas as categorias de classificação; e, por fim, essas categorias passam pelo processo de tratamento, inferência e interpretação dos resultados.

Para contextualizar a temática, o impacto ocasionado pela avaliação no emocional do personagem/aluno, logo lembramos algum momento de nossas vidas em que nos deparamos com algumas situações que ficamos apreensivos para um teste, uma entrevista, apresentação de trabalho, entre outros casos. Isto ocorre por não estarmos preparados ou pela própria insegurança de ser avaliado, e neste artigo refletimos sobre este assunto presente nas Histórias em Quadrinhos de Chico Bento, as consequências na dimensão socioafetiva, diante dos resultados obtidos e a pressão existente ao realizar as avaliações.

As Histórias em Quadrinhos se definem por uma sequência de desenhos, divididos em quadros, que seguem uma narrativa de acontecimentos para contar uma história, compostas por diversos elementos como: onomatopeias, balões, desenhos, cores e o enredo que a tornam lúdica, são usadas como entretenimento, mas também têm um grande teor didático, podendo ser utilizadas para a aprendizagem, pois as mesmas refletem fatos que estão presentes na sociedade. Conhecida como um meio de comunicação de massa, que propaga conhecimento por meio de livros, internet, televisão, jornais, entre outras mídias. As HQs, por meio de suas páginas, exibem um grande potencial que possibilitam a representatividade, contendo personagens diversificados e relacionados à realidade social; por esses aspectos escolhemos as histórias em quadrinhos para problematizar situações presentes no contexto escolar.

Destacamos a importância cultural e a influência pedagógica existente nas histórias em quadrinhos, essas não precisam ser vistas somente como entretenimento, mas sim, como um meio de 
comunicação e como ferramenta educacional que merece atenção por parte dos acadêmicos e educadores, capaz de oportunizar grandes questionamentos e reflexões.

Nos resultados deste estudo, compreendemos o impacto trazido pela avaliação da aprendizagem, a mesma sendo empregada de maneira equivocada, assim, contribuindo negativamente na condição socioafetiva do aluno, causando ao mesmo frustrações, medos e insegurança ao realizar um teste/prova, por sua vez retratando o insucesso da aprendizagem do personagem Chico Bento, situação que também ocorre em muitas salas de aula.

\section{METODOLOGIA}

A pesquisa se desenvolveu a partir do levantamento das tirinhas do personagem Chico Bento, elaborou-se a partir das representações de escola, com centralidade no processo de avaliação escolar e suas consequências no desenvolvimento da aprendizagem do educando. Para a constituição do corpus da pesquisa e obter os dados trazidos pelas tirinhas, utilizamos a análise semiológica (das imagens) para a validação do estudo e, segundo Penn (2013), seguimos as presentes etapas: a aplicação da escolha das imagens, neste caso as tirinhas do personagem Chico Bento, e consequentemente, identificação da fonte do material, que nesta pesquisa de centraliza no Aplicativo Banca da Mônica (2019), e assim estabelecemos em nossa fonte de dados escolhida. No aplicativo se encontram disponibilizadas as edições das revistas de Chico Bento dos anos de 1999 e 2000, contemplando 4 edições apresentadas no decorrer deste artigo.

O personagem Chico Bento, criação do cartunista brasileiro Mauricio de Sousa, surgiu em 1961, tendo 59 anos de histórias encantadoras e que promovem grandes reflexões aos mais diversos assuntos aos leitores. Em seus enredos, o autor busca trabalhar valores e refletir sobre fatos presentes na realidade de nossa sociedade. O personagem retrata a criança que vive no interior, com base na simplicidade, inocência e no amor pela natureza e os animais. Uma de suas características é a falta de interesse nos estudos. Em suas histórias estas dificuldades são abordadas com bom humor, enaltecendo que a maior preocupação de Chico, evidentemente, são as notas e o tão esperado dez. As dificuldades do aluno e o conflito da educadora em desenvolver o interesse no educando e em paralelo, atender às necessidades da turma, fica evidente.

Como fundamentação teórica, utilizamos os principais autores que abordam a temática da avaliação da aprendizagem, tais como: Hoffmann (1995), Esteban (2009), Vasconcellos (2008), Luckesi (2010) e Moretto (2010). Diante de seus discursos estabelecemos as informações para realizar a análise comparativa dos dados, juntamente com a experiência de classe da autora deste artigo, professora dos anos iniciais da educação básica, posso dizer que em minha trajetória profissional encontrei muitos alunos que apresentaram as mesmas emoções do protagonista Chico Bento, dentre elas o medo, ansiedade, instabilidade emocional, choro excessivo, comportamentos ocasionados pela insegurança ao realizar uma 
prova ou até mesmo de responder perguntas referentes ao conteúdo estudado, alimentado simplesmente pelo medo de errar ou uma futura reprovação.

\section{DISCUSSÃO E RESULTADOS}

A prova é uma característica permanente do processo de ensino, os alunos são avaliados constantemente pelos professores e cobrados pelos familiares para que os mesmos apresentem resultados satisfatórios. Esta pressão acerca da aprendizagem do educando pode soar negativamente, gerando inseguranças e refletindo nas notas do boletim. Diante desta perspectiva, temos o papel do educador, pois partilha com o estudante a responsabilidade pelo processo de aprendizagem, determinando que o foco do ensino não está somente no conteúdo, mas em favorecer um processo contínuo e efetivo de aprendizagem, percebemos que a professora da Escola da Vila Abobrinha parece não entender as frustrações do aluno e seu comportamento diante da avaliação. Dentre outras edições das histórias em quadrinhos de Chico Bento, além das tirinhas citadas ao longo deste artigo, apresentamos uma edição de 1993 (Figura 1), denominada “cenas impossíveis" que em certo período circulavam nos gibis da Turma da Mônica pela editora Globo, nesta ilustração o personagem se encontra desmaiado ao ser informado do resultado de sua avaliação, o tão esperado 10, com isso constatamos o impacto na dimensão socioafetiva do educando.

Figura 1: Cenas Impossíveis, 1993.

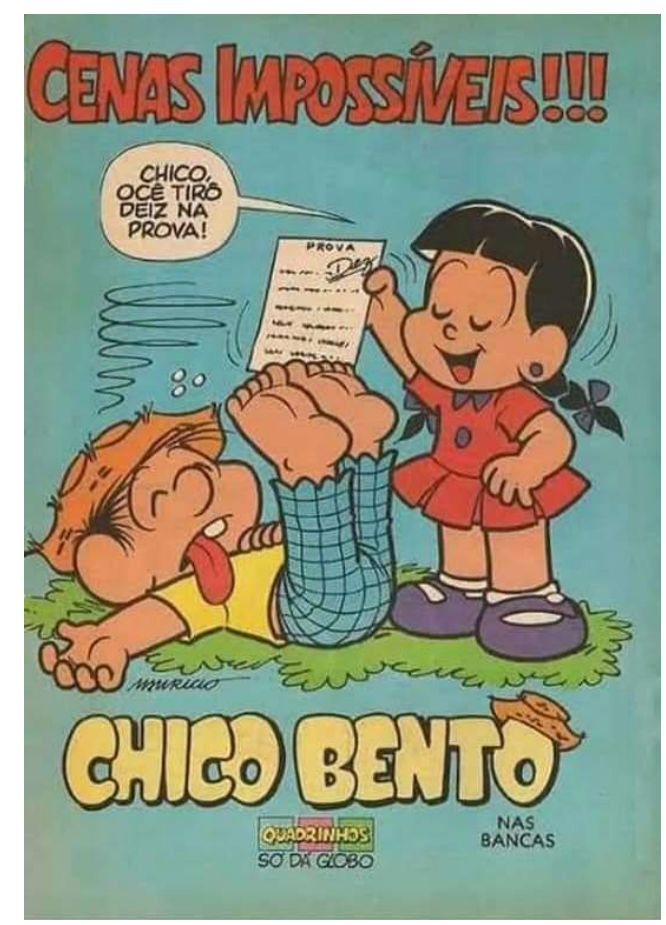

Fonte: Google imagens, 2020. 
Diante desta cena do personagem Chico Bento, notamos que as histórias em quadrinhos aproximam o leitor e os enredos apresentados são relacionados com situações vividas, este é o potencial das HQs trazer situações decorrentes do dia-a-dia, torná-las mais leves e com possibilidade de reflexão, onde o leitor se identifique, buscando amenizar e superar situações emocionais e sociais. Segundo Moya (1986, p.8), "através do humor, do riso, da aventura, do heroísmo, das boas ações, do bem contra o mal, da luta pela justiça contra a injustiça, dos pequenos contra os fortes e poderosos, os quadrinhos lutaram para construir um mundo melhor e mais justo socialmente." Nos identificamos com as histórias vividas pelos personagens, apresentando-se muito mais que um objeto de entretenimento, tornam-se um modelo para o desenvolvimento do pensamento crítico, assim colabora Weschenfelder (2011, p.12):

As HQs tornaram-se uma referência na formação de opiniões porque de maneira sutil e perspicaz colocam em debate as questões fundamentais das relações sociais e os dilemas morais com os quais todos os seres humanos normais se defrontam no dia a dia. Elas abordam, na forma exemplar de vivência do personagem, as questões de suma importância enfrentadas pelos seres humanos, tais como a responsabilidade pessoal e social, a identidade pessoal, a diferença; as questões atinentes, à alma, à mente e às emoções humanas, além de problemas bem concretos do cotidiano.

Por este motivo as histórias em quadrinho se caracterizam uma excelente ferramenta pedagógica, capaz de aproximar o aluno da aprendizagem significativa, principalmente na fase de alfabetização, pois auxiliam no processo de aprendizagem, onde educando se dinamize, promovendo o lúdico e o encantamento, desenvolvendo o imaginário e a criatividade de forma natural, levando a consolidação do hábito de ler, possibilitando a evolução da capacidade criadora do educando, permitindo a produtividade de forma dinâmica.

Agora que já contextualizamos a temática deste artigo, realizaremos a reflexão e diante das contribuições dos principais autores da área da avaliação da aprendizagem. O processo de avaliar tem como base o planejamento do educador e nem sempre é uma tarefa fácil elaborar uma prova, devemos levar em conta vários fatores, emocionais, o perfil da turma, o objetivo da avaliação e a clareza do conteúdo. Para que a avaliação não perca a sua real função de diagnosticar a situação da aprendizagem do aluno. No entender de Moretto (2010, p. 115):

A avaliação da aprendizagem é angustiante para muitos professores por não saberem como transformá-la num processo que não seja mera cobrança de conteúdos aprendidos de cor, de forma mecânica e sem muito significado para o aluno. Angustiante por terem de usar um instrumento tão valioso no processo educativo como recurso de repressão, como meio de garantir que uma aula seja levada a termo com certo grau de interesse.

No entender de Hoffmann (1995), a avaliação precisa ter como base a mediação e um olhar atento. Nesse contexto, o professor precisa agir, refletir e investigar sobre sua ação educativa constantemente, para depois disso, reformular sua prática. A avaliação precisa estar centrada no diálogo, na aprendizagem significativa (erro construtivo), juntamente com atividades lúdicas, que valorizam a 
criança em todas as suas linguagens e sensibilidades, com intuito de valorizar suas potencialidades. E segundo Luckesi (2010), a avaliação se caracteriza como um compromisso com a aprendizagem do educando, permitindo a investigação e possíveis intervenções e consequentemente compreensão da realidade do contexto geral da turma e individual.

A partir desta perspectiva, surge a necessidade do educador ter confiança na capacidade do educando aprender, entender que cada um tem seu tempo, fornecendo preparo e segurança e demais recursos que complementam a avaliação, para que essa não seja somente uma característica da escola, mas sim uma ferramenta pedagógica que tenha como principal objetivo a obtenção do sucesso do aluno, deixando as angústias e anseios de lado, oportunizando um clima acolhedor.

Nas Figuras de números 2, 3, 4 e 5 (apresentadas no decorrer deste artigo), podemos observar o impacto da nota no comportamento do estudante. Na Figura 1 (abaixo), o personagem Chico Bento se encontra em frustração, ao saber do resultado da prova de gramática, sendo a nota zero. No momento em que chega em casa se depara com uma sopa de letrinhas, aumentando seu descontentamento com o rendimento escolar. Além do sofrimento ocasionado pela prova, o aluno se depara com uma sopa de letrinhas, obviamente se questionando do resultado negativo obtido. Já na Figura 2 (abaixo), ao chegar na sala de aula, o aluno tenta conquistar a educadora com uma maçã, se não houvesse prova, mas como a avaliação estava confirmada, o menino come a fruta, como forma de desmerecimento à professora e reprovação ao sistema avaliativo, deixando a docente pensativa diante do comportamento do aluno. 
Figura 2 -Tirinha do Chico Bento, n 322/1999
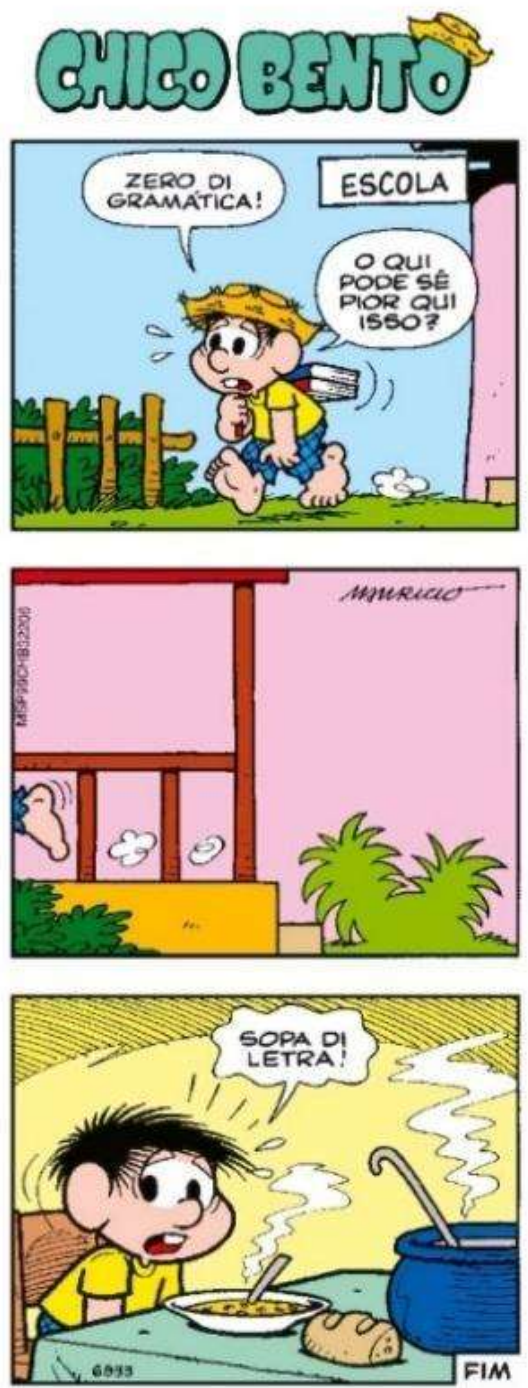

Fonte: Aplicativo Banca da Mônica, 2019.
Figura 3 - Tirinha do Chico Bento, n³40/2000
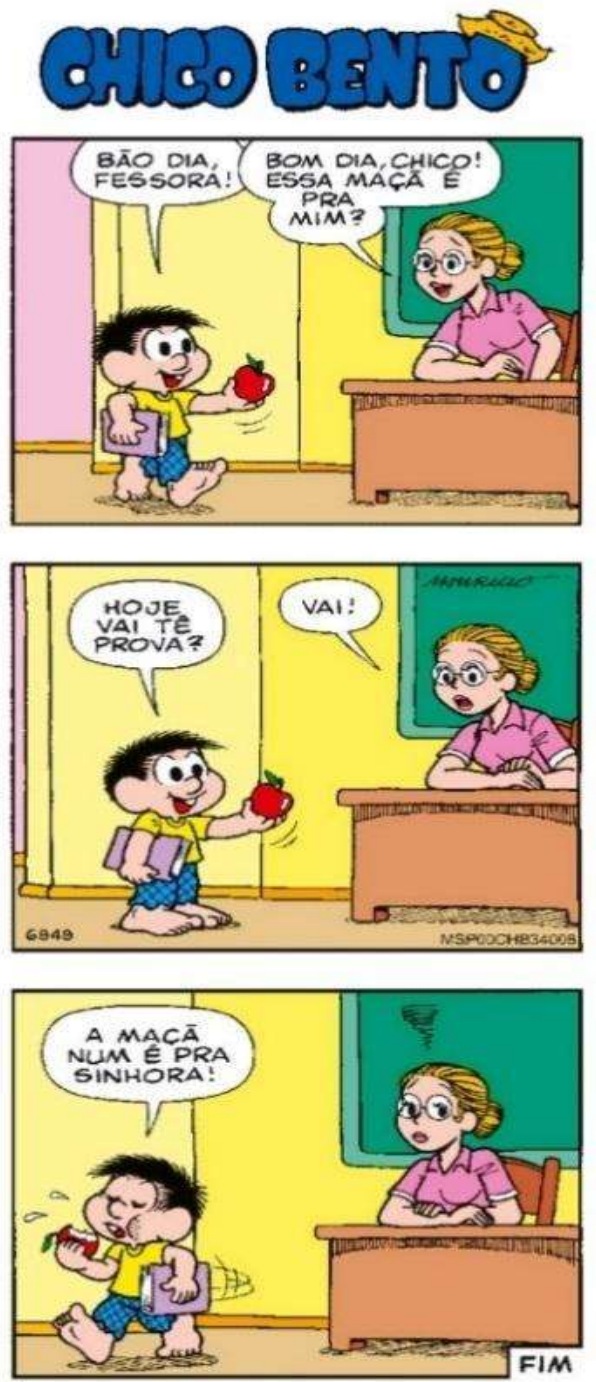

Fonte: Aplicativo Banca da Mônica, 2019.

Segundo o que está previsto nas Diretrizes Curriculares Nacionais para o Ensino Fundamental de 9 (nove) anos (BRASIL, 2010, p. 3), o conhecimento estabelecido para o currículo dos anos iniciais deve ser elaborado pela escola tendo como centralidade a transformação e formação do educando, assim colabora:

$\int 3^{\circ}$ Os conhecimentos escolares são aqueles que as diferentes instâncias que produzem orientações sobre o currículo, as escolas e os professores selecionam e transformam a fim de que possam ser ensinados e aprendidos, ao mesmo tempo em que servem de elementos para a formação ética, estética e política do aluno.

De acordo com Moretto (2010, p. 39), “Todo professor sabe que o momento da avaliação é aquele em que as emoções do aluno entram em ebulição. Nele se misturam sentimentos de ansiedade, medo, angústia, alegria, tensão, estresse etc.” Dessa forma, considerando-se a importância da avaliação no processo educativo, é necessária a criação de um ambiente facilitador e tranquilo de forma a minimizar a influência dos aspectos negativos no afetivo-emocional do desempenho do aluno. 
As tirinhas apresentadas acima demonstram o desconforto, a ansiedade e frustração. Para Perrenoud (2001), o contexto escolar afeta o humor e as ações das crianças, gerando insatisfações que se refletem em seu rendimento. Devemos compreender que a avaliação é uma ferramenta pedagógica, não uma cobrança de um modelo de aluno em relação ao nível classificatório de aprendizagem, e se afirmando como uma forma de modelar e doutrinar educandos, igualmente os aspectos apresentados na prova devem estar de acordo com o contexto de realidade da turma.

Referente a Figura 4 (abaixo), o protagonista aparece entusiasmado com a professora Marocas em relação às notas nas disciplinas de matemática, história e ciências, 10 em todas; de repente, o menino é acordado pela mãe, dizendo que o mesmo iria se atrasar para a escola, o desempenho incrível não passou de um simples sonho. Já em relação à Figura 5 (abaixo), Chico Bento se encontra apreensivo com o resultado da prova, relatando a educadora que uma palavra dela poderia fazê-lo feliz, então Dona Marocas fala: 10! E o aluno sai da escola pulando de felicidade.

Figura 4 - Tirinha do Chico Bento, no 347/2000
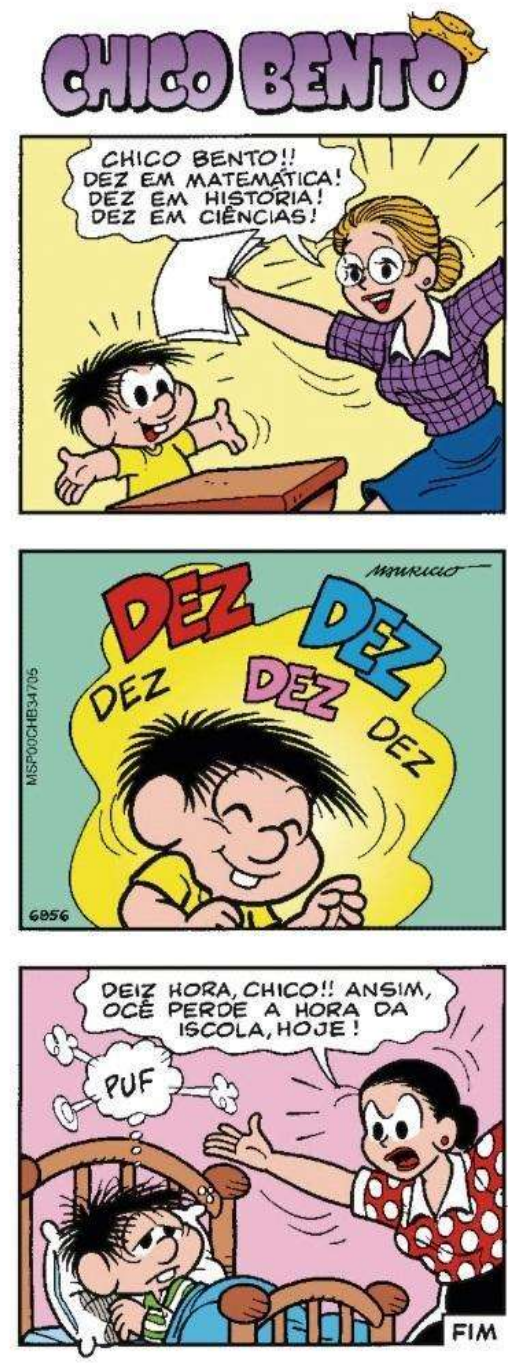

Fonte: Aplicativo Banca da Mônica, 2019.
Figura 5 - Tirinha do Chico Bento, no 353/2000
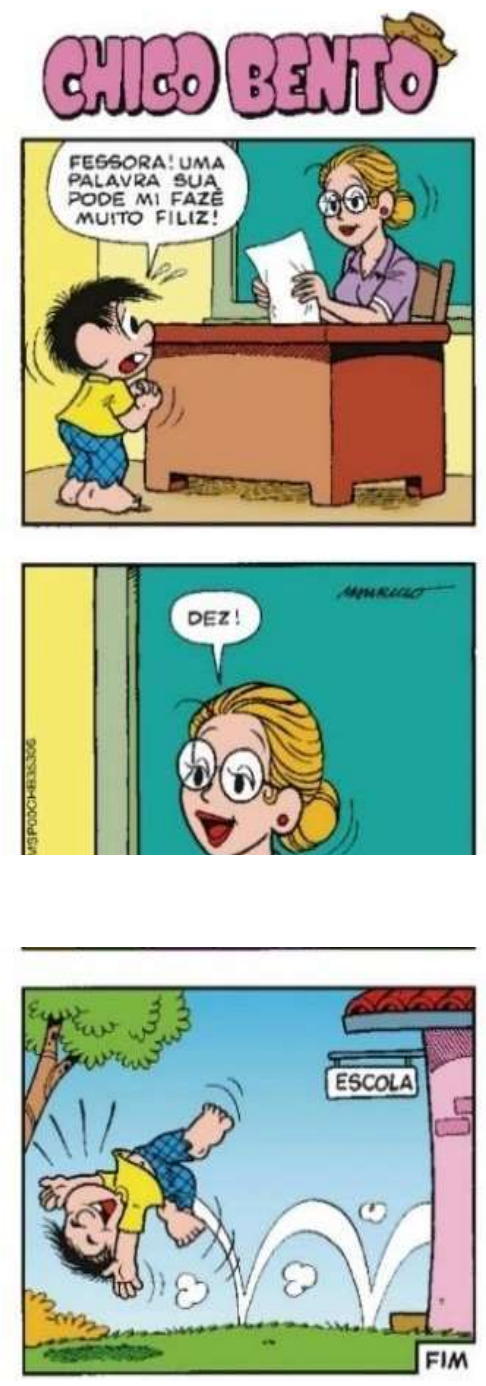

Fonte: Aplicativo Banca da Mônica, 2019. 
Ao descrever a situação vivenciada pelo personagem, novamente percebemos o peso da prova na vida do educando, sendo capaz de estimular ou retroceder o desempenho do educando. A avaliação em sua essência deve ser contínua e cumulativa, centrada na performance do aluno em relação a suas habilidades e desenvolver a sua capacidade de identificar, analisar, refletir, comparar, problematizar, argumentar, e capaz de reconstruir saberes.

Segundo Vasconcellos (2008, p. 131): "Desde muito cedo os professores foram perdendo o 'contato', a parceria, a cumplicidade, com os alunos; logo nas séries iniciais, a avaliação já foi se colocando como fator de distanciamento professor-aluno-objeto de conhecimento" (grifo do autor). Percebemos nos fragmentos das HQs que a educadora centraliza sua didática nas notas dos educandos, não proporcionando a aprendizagem significativa, baseada na realidade do sujeito. Para Esteban (2009, p. 52), avaliação concebe o horizonte para a construção do trabalho pedagógico e a evolução dos alunos com atraso da aprendizagem, complementando:

A centralidade dessa avaliação está no processo de regulação externa da dinâmica pedagógica, colaborando para a redução das possibilidades da escola refletir sobre seu trabalho, formular suas propostas de ação e estabelecer modos coletivos e democráticos de regulação do trabalho, com a finalidade de produzir práticas favoráveis ao processo aprendizagem-ensino.

Um dos focos da avaliação é o que ainda se pode mudar para que o aluno consiga desenvolver suas potencialidades. A proximidade do professor, o estabelecimento de objetivos, e a mobilização das capacidades e dos conhecimentos que possam auxiliar os alunos são fundamentais. Moretto (2010, p. 44) traz à tona o papel do professor como "mediador, facilitador e catalisador do processo de aprendizagem". Continua o autor:

Sua presença se faz absolutamente indispensável como elemento organizador do contexto de aprendizagem, com vistas a facilitar o processo de construção das representações pelo aluno. Fica, então, claro que o professor não é transmissor de conhecimento, e sim aquele que prepara as melhores condições para que sua construção se efetue.

Ao observar as figuras (as 4 acima apresentadas), dispostas neste eixo, consideremos como os resultados das avaliações modificam o comportamento do personagem demonstrando indiferença e frustração, o mesmo chegando a sonhar com o "dez"; nesta perspectiva, refletimos, a prova tem um peso maior do que a aprendizagem significativa? Se a resposta for sim, o ato de avaliar priva-se de sua finalidade e o aluno perde o seu Direito à aprendizagem. 


\section{CONSIDERAÇÕES FINAIS}

A partir das informações apresentadas neste artigo sobre o impacto do resultado da avaliação na dimensão socioafetiva do estudante, é possível lançar alguns questionamentos com o objetivo de proporcionar reflexões diante as práticas pedagógicas que acercam a avaliação da aprendizagem em seu real papel, assim percebemos o impacto da avaliação na condição socioafetiva do aluno, causando ao mesmo angústias, frustrações, medos e insegurança ao ser submetido a um teste/prova, por sua vez prejudicando o processo de ensino/aprendizagem do aluno. Sendo assim, o processo de avaliação descrito nas Histórias em Quadrinhos influencia negativamente no desenvolvimento socioafetivo do personagem Chico Bento, criando muitas expectativas e frustrações diante da prova, privando o mesmo de um potencial rendimento.

Como educadores, devemos refletir diante à didática da professora Marocas e da nossa prática pedagógica, ter referência em oportunizar um clima facilitador e acolhedor para o desenvolvimento da aprendizagem, que o educando seja protagonista em seu processo de conhecimento, não vítima de um sistema classificatório e opressor de ensino. Surge a necessidade de olhares atentos para avaliação escolar, utilizada de forma correta, e a criação de um currículo pedagógico justo e dentro da realidade da turma, e assim, acima de tudo ter cuidado e responsabilidade com o nosso futuro, os alunos.

\section{REFERÊNCIAS}

BARDIN, Laurence. Análise de conteúdo. São Paulo: Edições 70 LDA/Almedina Brasil, 2016.

BRASIL. MINISTÉRIO DA EDUCAÇÃO. CONSELHO NACIONAL DE EDUCAÇÃO. CÂMARA DE EDUCAÇÃO BÁSICA. Resolução n 7, de dezembro de 2010. Fixa Diretrizes Curriculares Nacionais para o Ensino Fundamental de 9 (nove) anos.

ESTEBAN, Maria Teresa. Provinha Brasil: desempenho escolar e discursos normativos sobre a infância. Sísifo. Revista de Ciências da Educação, RJ, p. 47-56, 2009.

HOFFMANN, Jussara. Avaliação: mito \& desafio: uma perspectiva construtivista. 16. ed. Porto Alegre: Educação \& Realidade, 1995.

LUCKESI, Cipriano Carlos. Avaliação da aprendizagem escolar. 21. ed. São Paulo: Cortez, 2010.

MORETTO, Vasco Pedro. Prova: um momento privilegiado de estudo, não um acerto de contas. 9. ed. Rio de Janeiro: Lamparina, 2010.

MOYA, Álvaro de. História da história em quadrinhos. Porto Alegre: L\&PM, 1986. 
MSP, (Mauricio de Sousa Produções). Aplicativo Banca da Mônica (2019). Disponível em: https://play.google.com/store/apps/details?id=air.br.com.mauriciodesousa.caixadequadrinhos\&hl=pt _BR . Acesso em: 03 de mar. 2019.

PENN, Gemma. Análise semiótica de imagens paradas. In: BAUER, Martin W; GASKELL, George. Pesquisa qualitativa com texto, imagem e som. Petrópolis, RJ: Vozes, 2013, p.319 - 342.

PERRENOUD, Phillipe. Avaliação: da excelência à regularização das aprendizagens: entre duas lógicas. Porto Alegre, Artmed, 1998.

SOUSA, Mauricio. Cenas impossíveis. São Paulo: Editora Globo, 1993.

SOUSA, Mauricio. Chico Bento. São Paulo: Editora Globo, nº 353, agosto/2000.

SOUSA, Mauricio. Chico Bento. São Paulo: Editora Globo, nº 340, fevereiro/2000.

SOUSA, Mauricio. Chico Bento. São Paulo: Editora Globo, nº 347, abril/2000.

SOUSA, Mauricio. Chico Bento. São Paulo: Editora Globo, no 322, maio/1999.

VASCONCELLOS, Celso dos S. Avaliação da aprendizagem: práticas de mudança: por uma práxis transformadora. 9. ed. São Paulo: Libertad, 2008.

WESCHENFELDER, G. V. (2011). Aspectos educativos das histórias em quadrinhos de superheróis e sua importância na formação moral, na perspectiva da ética. Mestrado em Educação, Centro Universitário La Salle, Canoas, RS, Brasil. 